\title{
Interpreting Students' Experiences with Academic Disappointments Using Resourcefulness Scores as a Lens
}

\begin{abstract}
Most postsecondary students have to deal with academic disappointments at some point in time, with many of them succumbing to their anxieties and failing to learn from these lived experiences. Our study aimed to understand why and how disappointments unfolded in a sample of 20 undergraduate students, using a design whereby interview text was concurrently analyzed across the continuum of learned resourcefulness measured using Rosenbaum's SelfControl Schedule in conjunction with an inductive, data-driven coding and theme-generation perspective. Reasons for attending university, attributional style, coping and learning, and perceptions of others markedly differed for high- and low- resourcefulness scorers. Whereas high-resourceful scorers used academic disappointments as a motivator to engage in more effort and problem-solving strategies, low scorers ruminated and tried to forget about them. Suggestions are provided on ways to effectively help students become more resourceful and in control of their studies.
\end{abstract}

\section{KEYWORDS}

learned resourcefulness, academic disappointments, explanatory style, perceived control

\section{INTRODUCTION}

Imagine the following scenario. Julia, a freshman student, is sitting in a big lecture hall, anxiously waiting to receive the results of her first math exam. Finally, after what felt like a painfully long lecture, the professor starts calling students to pick up their exam. Julia's heart beats faster and her palms begin to sweat as her name is called. She is a bit nervous to learn her mark, although more than anything, she is eager and excited. After all, she knows she did amazingly well ... Then it happens. Feelings of disappointment begin to flood her body. "C minus? No, no, that can't be right," she thinks to herself, as she frantically flips through each page to find the sure evidence that this exam in fact belongs to someone else. But she quickly comes to the realization that this is her exam. The professor made no mistake.

According to Rosenbaum's (1990) model of self-control, after Julia's immediate emotional reaction, what happens next depends on her secondary appraisal of this situation. If Julia decided that she was okay with a C-, her life would continue on as usual. Alternatively, however, if C- was not up to her standards and she recognized the need for a plan of action, having a relatively large repertoire of general resourcefulness skills would make it easier for her to engage in behavioral change (e.g., begin to distribute her study time for tests and exams over days versus at the last minute). To measure general resourcefulness skills, Rosenbaum (1980) developed the Self-Control Schedule. It assesses the use of positive self-talk to remain calm when stressed; the application of problem-solving skills such as planning 
and anticipating consequences; the ability to complete unpleasant tasks before engaging in more pleasant ones; and the understanding that self-control behavior requires personal willingness and effort. The model further acknowledges that unforeseen setbacks often occur in the pursuit of goals; therefore a positive explanatory style and high self-efficacy provide individuals engaging in self-control with continued momentum.

Past quantitative studies on goal pursuit, using the Rosenbaum Self-Control Schedule (SCS), find that scores are unrelated to perceptions of stress (e.g., Akgun, 2004), severity of illness or pain (e.g., Rosenbaum \& Ben-Ari Smira, 1986), and motivation (e.g., Lévesque, Gauvin, \& Desharnais, 2003). Instead, it is reported that individuals with higher scores on the SCS are more successful at quitting smoking (Katz \& Singh, 1986), exercising regularly (Lévesque et al., 2003), and sustaining a healthy weight following a weight-loss program (Kennett \& Ackerman, 1995), as well as managing acute and chronic health issues (e.g., Huang et al., 2007; Menshadi, Bar-Tal, \& Barnoy, 2013; Rosenbaum \& BenAri Smira, 1986). Furthermore, using a quasi-experimental design where failure was not contingent upon participants' actual responses, it was found that those scoring higher on the SCS were less likely to give up and experience feelings of helplessness (Rosenbaum \& Ben-Ari, 1985).

Within the academic domain, quantitative studies have reported that students scoring higher on the SCS were more effective at coping with academic stress in order to maintain good grades (Akgun, 2004; Akgun \& Ciarrochi, 2003). For instance, Akgun and Ciarrochi (2003) found no difference in academic performance between Australian undergraduates scoring low and high on the SCS when stress was low; but, when stress was high, students scoring low on the SCS had significantly poorer grades than did those who scored high. Furthermore, other research has shown that what separates the high- from the low-scoring students on the SCS in these types of investigations are greater beliefs in academic ability, an explanatory style that attributes academic disappointments less to a lack of ability or effort, and effective reliance on academic-related positive self-talk and problem-solving strategies (Kennett \& Keefer, 2006).

Since its inception in 1980, Rosenbaum's SCS continues to be a popular instrument for assessing individuals' use of effective coping strategies to overcome a wide variety of everyday life issues. Evidence for its construct-related validity and reliability has been well documented, including convergent validity, divergent/discriminant validity, concurrent validity, test-retest reliability, and internal consistency (Kiefer, 2002; Redden, Tucker, \& Leslie, 1983; Rosenbaum, 1980; Zauszniewski, 1997), across student and community samples and for languages including, but not limited to, Hebrew and English (Rosenbaum, 1980), Thai (Boonpongmanee, Zauszniewski, \& Boonpangmanee, 2002), Japanese (Nakano, 1995), Chinese (Ngai, Chan, \& Holroyd, 2008), and French-Canadian (Lévesque et al., 2003). This backing has allowed investigators to concurrently analyze qualitative text, using individuals' scores on the SCS as a resourcefulness lens, with great success (Fast \& Kennett, 2015; Kennett, O’Hagan, \& Cezer, 2008). For example, in their study on strategies chronic pain sufferers acquired from a past pain management program, Kennett et al. (2008) found that people scoring low on the SCS talked about dealing with their pain in a passive and reactionary way, whereas those scoring high on the SCS described ways they were currently using and adapting the active coping strategies that they were taught in the program. Fast and Kennett's (2015) study on exercise maintenance discovered that the conversations of individuals scoring low on the SCS were on excuses for not meeting their goal to 
exercise more regularly and were void of the self-regulatory strategies that high scorers described employing to sustain consistent activity.

The insights gained by the above qualitative studies would not have happened without the concurrent use of SCS scores. By using the scores as a lens for interpreting participants' experiences, these researchers were better able to comprehend why some participants found it easier to manage complications whereas others got stuck and had difficulty coping.

To our knowledge, no study has qualitatively explored students' experiences with academic disappointments using Rosenbaum's SCS as a lens. Although the specific details of what constitutes an academic disappointment may vary from one student to another, we reasoned that this type of everyday life obstacle would be relatively common for most students regardless of their score on the SCS and that students' discussion of such incidents would serve to deepen our understanding of the specific thoughts or beliefs and behavioral strategies that either help or hinder the resolution of these events and what they learned from them. Knowing this would also offer ways for academic skill centers to help students deal with setbacks. In order to also provide participants with the opportunity to reflect on their accomplishments, they were asked to talk about their academic successes, too.

\section{METHOD}

\section{Participants}

Twenty undergraduate students from a small liberal arts university in Ontario, Canada, participated in this study. The sample was predominantly female ( 85 percent), unmarried ( 90 percent), Canadian citizens (95 percent), working while attending university ( 55 percent), registered as a fulltime student (95 percent), in their first year of study (50 percent), lived off campus (65 percent), and majoring in psychology or had a joint psychology major (60 percent). All participants were emerging adults, with ages ranging from 18 to 23 years.

\section{Procedure}

Undergraduate students were recruited using an internal online research participant management system whereby they could sign up for the study, if interested. Consenting participants first completed Rosenbaum's SCS and were subsequently interviewed by Rebecca Martin in a comfortable, quiet, and private office space. At no point during the interview process did Martin know the participants' answers to the schedule's items. After the interview, participants were provided with a debriefing form containing contact information and a list of university resources and received a bonus credit toward an introductory psychology course. This study was approved by the university's research ethics board.

\section{Rosenbaum's Self-Control Schedule}

General learned resourcefulness was measured using Rosenbaum's SCS. The schedule consists of 36 items and uses a six-point Likert scale ranging from -3 ("very uncharacteristic of me") to +3 ("very characteristic of me"). Items include such statements as the following:

- "When I am faced with a difficult problem, I approach it in a systematic way" (problemsolving item); 
- "I prefer to finish a job that I have to do before I start doing things I really like" (delay of immediate gratification);

- "When I realize that I am going to be unavoidably late for an important meeting, I tell myself to stay calm" (positive self-talk); and

- "If I carried the pills with me, I would take a tranquillizer whenever I felt tense and nervous" (an understanding that self-control behavior takes personal effort, reversescored item).

After reverse scoring, responses to each item are summed to produce total scores. A higher score indicates a greater repertoire of general resourcefulness behaviors.

\section{Semi-structured interview}

Audio-recorded interviews were completed by Martin and varied in length from 13 to 70 minutes. An interview guide was used to help focus on the topic at hand (academic disappointments and successes) and ensure consistency in the delivery of questions across interviews (the structured part of the interview). However, participants were encouraged to have control over their interviews, discussing their experiences freely and in no predetermined order, and addressing additional questions that were not in the interview guide (the semi- aspect of the structure).

Demographic information was collected at the beginning of the interview to provide context to students' experiences and help develop rapport with the participants. Participants were then asked to broadly describe their experiences with academic disappointments and successes ("Please tell me about your experiences with academic disappointments/successes") and were given the choice as to which one (disappointments or successes) they wanted to talk about first. Depending on the focus, depth, and detail of participants' responses to this broad question, follow-up probe questions were utilized to enhance the specificity and richness of the interview data. An example probe question is the following: "Can you describe in detail one specific experience you've had with academic disappointment or success?” Broad categories of probe questions included description of a particular academically disappointing/successful experience; explanations for why a disappointment or success occurred; feelings surrounding a disappointment or success; coping with disappointment or success; similarities or differences between their experiences and those of their peers; and personal growth or learning following disappointments or successes. It is worth noting that all participants, regardless of their score on the SCS, said they had experienced academic disappointment, with many participants sharing more than one account of disappointment. Moreover, all participants described more recent academic disappointments or successes they had experienced while at university. The few students who additionally mentioned past disappointments or successes from their elementary and secondary school years did so to contextualize their university experiences. For instance, one student said she had been on a "winning streak" in her last year of high school, contextualizing her frustration with a particular university disappointment and explaining why her university disappointment had occurred (the winning streak did not continue). 


\section{Thematic analysis of the interviews across the continuum of general resourcefulness}

Interviews were analyzed using thematic analysis. Specifically, open and axial coding was performed, resembling Corbin and Strauss's (2008) grounded theory approach. We independently read through all of the interviews, making notes on initial impressions and participants' use of emotion- and action-oriented coping responses, prior to incorporating the SCS scores and engaging in a more thorough coding process.

Although we sought detailed and in-depth descriptions of the lived experiences and perceptions students had with disappointments (phenomenological data), we were ultimately guided by a critical realist epistemology (see Willig, 2013), whereby resourcefulness scores were used to help interpret students' experiences. Researchers adopting a critical realist epistemological stance believe there to be an existing "truth" or "reality" to discover about a given topic, while simultaneously acknowledging that this "truth" can never be fully uncovered due to human limitations and biases. We adopted a critical realist stance for this study because we believe there to be real differences in the experiences that high- and lowscoring students have with academic disappointments and, by contrasting the rhetoric of low- and highscoring students, we would be capturing a closer approximation to the truth. We also believe students' SCS scores are a reasonable approximation of their true level of general resourcefulness, and therefore we used their scores as a lens for interpreting the interview text.

Total scores ranged from -16 to 51 , with a mean score of 18 and a standard deviation of 22, and are comparable to the values found in other recent studies (e.g., Fast \& Kennett, 2015). Also consistent with other investigations (Fast \& Kennett, 2015; Kennett et al., 2008), scores clustering between -16 and 9 were representative of a low-scoring group, 14 and 27 were representative of a mid-scoring group, and 38 and 51 were representative of a high-scoring group. Table 1 provides each student's score and group classification.

The coding process started with the interviews at the extreme ends of the continuum. Martin and a practicum student independently openly coded the interviews and met regularly to examine coding consistencies. In line with descriptive phenomenological techniques, an effort was made to emphasize "the psychological dimension of experience" (Giorgi, 2009, p. 131), paying attention to behaviors, feelings, thoughts, attributions, motivations, coping strategies, and other individual-level phenomena. Next, Martin and the practicum student categorized the open codes into axial codes. Open and axial codes were ultimately data-driven (inductive), rather than being decided a priori (deductive), even though resourcefulness scores were used as a lens through which to understand, compare, and contrast the interviews. Congruent with previous research (e.g., Fast \& Kennett, 2015; Kennett et al., 2008), final themes were based on the differences between high and low scorers, given that mid-scorers' rhetoric was a blend of that articulated by the other two groups. Saturation was achieved early in the analysis, which is not uncommon for research utilizing an inductive, data-driven coding and themegeneration perspective with the purpose of creating descriptive codes based primarily on the explicit meanings in the language used by the participant (e.g., Ando, Cousins, \& Young, 2014; Francis et al., 2010; Guest, Bunce, \& Johnson, 2006). The final step of the analysis was rereading the interviews to ensure themes were grounded in the data. 
Table 1. Rosenbaum Self-Control Schedule scores and classification as low-, mid-, or high-scoring ( $\mathrm{N}=\mathbf{2 0}$ )

\begin{tabular}{lll}
\hline STUDENT & SCSSCORE & CLASSIFICATION \\
\hline 3 & -16 & low \\
5 & -15 & low \\
17 & -10 & low \\
4 & -8 & low \\
16 & -8 & low \\
7 & 5 & low \\
$14[$ negative case] & 7 & low \\
6 & 9 & low \\
9 & 14 & mid \\
11 & 15 & mid \\
8 & 18 & mid \\
10 & 21 & mid \\
19 & 27 & mid \\
1 & 38 & high \\
13 & 41 & high \\
15 & 41 & high \\
18 & 41 & high \\
20 & 42 & high \\
2 & 46 & high \\
12 & 51 & high \\
\hline
\end{tabular}

Key: SCS score = general learned resourcefulness score; classification = each student's classification as low-, mid-, or high-scoring on the SCS for the current study

\section{RESULTS AND DISCUSSION}

\section{Theme 1: Is the grade all that matters? Reasons for attending university and grade expectations}

Although none of the interview guide questions directly asked about motivations for attending university, this theme was present in the interviews of all the students. Six of the seven low scorers were focused on their final grades, particularly seeking passing final grades (e.g., "As long as I'm passing, it doesn't really matter"; S6, score of 9). The four lowest-scoring students were worried about financial and other consequences associated with failing, providing no insight about how they could rectify these uncertainties (e.g., "I don't know what to study for ... I'm just scared. I have to do really good or this gets onto my transcript and all my tuition money goes to waste"; S17, score of -10).

The high scorers also cared about their grades, but six of them additionally discussed a love of learning, a desire to challenge themselves, or an aspiration to apply what they had learned to other contexts (e.g., "I enjoyed learning about the bones and muscles ... It's important to apply yourself and study as hard as you can"; S20, score of 42). It was clear these students had a sense of purpose for attending university that went beyond attaining good grades. Moreover, these students felt "[p]ride, I have pride in my work" ( $\mathrm{S} 1$, score of 38 ) and "when I see that grade, I'm going to be very happy ... I could have been doing other things but I stayed dedicated and I stayed focused and I applied myself" (S2, score of 46). 
Concentrating on why a goal is important - that is, the end product, such as final grade - can heighten a fear of failure and intensify discrepancies between desired and expected outcomes, all of which have been linked with greater procrastination around initiating and completing a goal (Fishbach \& Choi, 2012; Freund \& Hennecke, 2012). Focusing on how to achieve the goal instead provides more frequent opportunities for positive reinforcement and increased feelings of self-efficacy when smaller and more manageable goals are met. In short, the process itself becomes enjoyable (Krause \& Freund, 2014) and fosters progress and persistence toward the goal (Fishbach \& Choi, 2012).

Similarly, Kennett, Reed, and Stuart (2013) found that intrinsically oriented reasons for attending university (e.g., a desire to learn, self-growth, and personal interest), rather than extrinsically motivated reasons (e.g., delay responsibilities, societal expectations) predicted greater academic resourcefulness and better adjustment in university. A significant positive relationship between masterybased goals with general and academic resourcefulness has also been observed (Kennett \& Keefer, 2006). The findings from the present study extend evidence to this body of research.

\section{Theme 2: Helpful or helpless? Self-blame helps or hinders motivation depending on resourcefulness}

Nearly all students scoring low or high on the SCS blamed themselves for at least one of their past academic disappointments, although the nature of this self-blame varied for low- and high-scoring students in terms of its exact source (i.e., a lack of effort or preparation or a lack of ability) and the subsequent generated feelings of helplessness or motivation. High scorers' self-blame focused on a temporary lack of effort or unstable effort or preparation, not on a lack of ability. For these high scorers, recognizing their role in failure motivated them to put resourcefulness strategies into action to prevent history from repeating itself (e.g., "It's directly my responsibility ... And it's not so much disappointment as, 'Stop being a lazy student and buckle down'”; S18, score of 41). Enacting resourceful behaviors that addressed the problems causing their poor academic performance allowed these students to let go of their self-criticisms and feelings of disappointment and move forward with their studies (e.g., "There was a time I forgot to do [a weekly quiz] and I felt really bad. I was devastated, and after that I made sure I put up posters in my room saying 'Do psych quiz before Thursday!'; S2, score of 46).

Conversely, low scorers conveyed helplessness following self-blame, adopting an attitude of "why bother trying, I'm just going to fail anyway." For example:

- "I beat myself up about almost everything I do ... I might fail a test, I might half ass an essay, and I don't study harder after that, even if getting a bad grade ... I've gotten used to disappointment so much that I've always brushed it off like, 'Maybe next time I will do better,' but I don't even try to get better" (S4, score of -8)

- "It's a vicious cycle because once you start beating yourself up about one [disappointment], you don't think clearly ... so you do poorly on [the next assignment] ... so I was like, 'Well I'm not going to do well so why am I even trying?'” (S3, score of 16).

Low scorers perceived "ability" as having an innate capacity to "understand [the material] right away," and they had beliefs such as "[i] f I understand something I don't need to work hard and I do well. But if I don't understand something, I don't really want to work hard because I feel like I just won't get it” (S7, 
score of 5). Not only did the low-scoring students believe they lacked the ability to understand more difficult course material and attain good grades even if they tried, but they also had an aversion to working hard academically (e.g., "As long as I understand the content, I'll still keep reading more. But as soon as I get stuck on one thing, I just get so distracted, I just don't want to go through the process of figuring it out"; S17, score of -10). Even when these students wanted to adopt a more productive work ethic, they felt that doing so was not within their power, thus furthering their feelings of helplessness, frustration, and self-blame (e.g., "I was feeling mad at myself for procrastinating ... I always find that I procrastinate so much, and I try to get rid of that habit, but it always comes back"; S4, score of -8). Thus, low-scoring students in this study had three similar yet distinct sources of helplessness or lack of perceived control regarding their effort and ability attributions: they had a very difficult time staying focused and persevering with difficult or unpleasant material; they felt powerless with respect to changing poor study habits; and they believed that even if they did try they would still do poorly.

Moreover, three low scorers described in detail how other students effectively took charge of disappointments, yet never described modeling these same behaviors (e.g., "[My friends] will work harder on the next assignment [if they did poorly] ... I would just slack off even more. [And unlike them] I won't analyze and try to figure out what went wrong"; S17, score of -10). Paradoxically, these students felt lost, as they did not fully understand why they were failing and what to do differently (e.g., S17 repeatedly said “I just don't know why I keep failing”). This lack of understanding represents yet another source of helplessness, although not necessarily one based in self-blame attributions.

Intriguingly, the attribution-motivation and attributional retraining work of Weiner, Perry, and others suggests that students who attribute academic disappointments to internal and controllable reasons - namely, poor effort - feel more motivated to persevere with their studies (e.g., Haynes, Perry, Stupnisky, \& Daniels, 2009; Perry, 2003; Weiner, 1979; 1986). The interviews of the high scorers in the present study corroborate this line of thought. These students took direct responsibility for their lack of effort (i.e., viewed it as an internal source of failure) and felt confident in their ability to control future academic outcomes by means of adopting a stronger work ethic and more effective study strategies (i.e., viewed it as a controllable source of failure). The low-scoring students also blamed themselves for their lack of effort but thought that putting in effort or changing bad study habits was not fully within their control and, perhaps even more problematic, had "learned" that it ultimately did not even matter how hard they tried, they did not have the ability to succeed and would just fail anyways (i.e., they demonstrated learned helplessness). In fact, for these students, lack of effort resembled lack of ability in Weiner's model - that is, an internal and uncontrollable source of failure.

Similarly, quantitative studies on the self-control model have found that students with lower SCS scores are more likely to have a pessimistic explanatory style (e.g., Kennett \& Keefer, 2006; Kennett et al., 2013; see Seligman 1991). Comparable to the attributions in our sample, lower scorers in these studies were more likely to attribute poor performance to the combination of stable ("I always do poorly on this task"), internal ("I am not very smart"), and global factors ("I do poorly in everything I do"). Seligman (1991) argues that this attributional style can lead to the generalized belief that all control has been lost and the refrainment from engaging productively in a wide range of activities.

Encouragingly, two low scorers were trying to break out of this cycle of helplessness by being, as Neff (2003) would describe, more self-compassionate. S5, with a score of -15, was in the university's Fresh Start program, which aims to promote academic confidence and build academic skills. During the 
first half of this student's interview, she described "beating myself down" for failing a course and "hitting rock bottom," but later in the interview her tone changed to one of self-kindness and perseverance: "I'm adjusting more because I'm [in the Fresh Start program and] . . even though I failed most of my courses in the first semester, it didn't bog me down like it did last year and I just picked myself up." Similarly, S16, with a score of -8 , was breaking out of the cycle of helplessness by reminding herself of her grandfather's sage advice: "It [went from my thinking] 'Maybe you're not smart enough' [to remembering] my grandpa saying, 'Just keep pushing, you're smart, you've proven it to yourself, you can do it.” Interestingly, it was an outside source (the Fresh Start program and grandpa) that motivated these changes.

To what extent these acts of self-compassion eventually translated into better grades for these two students is uncertain. Neither S5 nor S16 described the specific academic resourceful behaviors they were using to improve their grades, discussing vague strategies instead (e.g., "They told me to take different approaches to things ... It might work for one thing but it's not always going to work for the other ... and I have to evaluate and check and just all around look"; S16, score of -8). Also, S5 indicated that she failed most of her first semester courses while in the Fresh Start program. Supporting that a selfcompassionate response to failure does not directly translate to higher grades, a recent study found that, regardless of self-compassion grouping, those classified as high scorers on the SCS were engaging in the most academic resourceful behaviors, with more engagement in these behaviors being uniquely associated with higher grades (Martin \& Kennett, 2018). Moreover, a nonsignificant relationship between self-compassion and grades has been reported in other studies (Breines \& Chen, 2012; Neff, Hsieh, \& Dejitterat, 2005). Thus, a self-compassionate mindset alone cannot produce better grades; it appears that one also needs to be academically resourceful.

\section{Theme 3: Attributions for academic disappointment and success beyond self-blame}

Aside from blaming themselves, students across the continuum of scores listed a variety of external reasons for experiencing certain academic disappointments. Low scorers directed blame and anger toward specific people or "the university system" for producing some of their poor grades (e.g., “The first time I couldn't submit a project [on Blackboard] and they wouldn't accept it. I thought, 'that's not fair' and felt very angry towards the prof, the TA, the school itself"; S3, score of -16). Several low scorers blamed their disappointments on poor teaching, believing the teacher was responsible (e.g., "In high school I had bad teachers. I handed in one assignment in pencil and [the teacher] said, 'It doesn't have to be in pen, don't worry about it.' Then for the next assignment, I did it in pencil and he took 22 percent off"; S6, score of 9) or knowingly using this attribution as an excuse for their own poor work ethic (e.g., "I find the prof doesn't explain it a whole lot... Sometimes [other students] blame the teacher or the prof for not really explaining [the material], which is similar to me. I guess most people are pretty much the same, they don't really like to take the blame for not working hard"; S7, score of 5). Other low scorers blamed their poor work ethic on their peers/friends (e.g., "I had wanted to study, but I was with a good group of friends and we always went out... And you don't want to say that you're not going out with [friends] because you want to study"; S4, score of -8). Noteworthy, "poor teaching" and "blaming others" (e.g., peers, the university system or the teaching assistant) are missing from a commonly used explanatory style for academic failure scale (Kennett \& Keefer, 2006) and are therefore components worth incorporating in such scales. 
A couple high scorers also said the professor or teaching assistant played a role in a past disappointment; however, they did not exhibit the same anger as did the low-scoring students, and one of them simultaneously acknowledged her role in her disappointment: "There's always multiple reasons [for disappointments]. Yeah, [the professor] didn't teach well but I also could have gone out and worked harder to get a tutor... done something more about it" (S15, score of 41); and "I really liked my [teaching assistant] ... it's just for the exam she said we should study main concepts and theories ... [but for the actual exam] we needed to know authors and names of papers ... I put a lot of effort into that class and then the exam brought me down a good 10 percent" (S13, score of 41$)$.

A few low-scoring students said they put in the effort yet received a disappointing grade. One such student said she had studied hard for a test and was frustrated when she did poorly: "For my anatomy midterm, I studied really hard all reading break, and I got a 50, and some guy in my res, he never shows up to class, he only studied the night before. He got an 88 . Because he's a genius. So that sucked" (S6, score of 9). This remark once again highlights the low scorers' belief that innate ability outweighs effort, as discussed above in relation to theme 2 .

High scorers adopted a belief that disappointments are a natural part of life and can occasionally happen even when hard work had been exerted due to factors such as a difficult assignment or tough marking scheme (e.g., "Sometimes those things happen where you put in the effort and you thought you did really good and then it's like, 'What went wrong?' Maybe it was more my fault, maybe I didn't live up to the expectations that were expected for that specific assignment, maybe the grading was just harder that time"; S2, score of 46). Interestingly, "task difficulty" is typically thought of as an external and uncontrollable source of failure (e.g., Weiner, 1979; 1986), yet the high scorers still felt responsible for not meeting the markers' expectations and living up to the challenges of the task and were motivated to work harder next time in order to succeed, ultimately perceiving this source of failure as being more internal and controllable.

Other reasons low scorers viewed as responsible for their academic disappointments included course material difficulty, lack of enjoyment, and external factors that compromised their ability to engage in resourceful behaviors (e.g., "I only had three classes at the time, so I had more time to work on it, but I didn't because I didn't enjoy it ... I feel like I just won't get it”; S7, score of 5). Similarly, these students often believed their successes resulted from factors beyond their immediate control: "I think [my successes] are attributed strictly to liking the course material" (S3, score of -16); and "[My success happened because] I think I just got lucky" (S6, score of 9).

Moreover, five low scorers assumed that past academic successes would lead to future academic successes in other courses and that the amount of effort required for maintaining successful grades could be subsequently reduced (e.g., "I wasn't the best student until last year of high school where I really pulled it together. So I was hoping that winning streak would follow on [but] it didn't"; S5, score of -15). In sharp contrast, the high scorers believed that "If I did bad ... I have to work harder on the next paper . .. But if I did good ... I know I should put the same or more amount of effort if I want to achieve the same grade" (S12, score of 51). Indeed, the high scorers attributed their academic successes to personal commitment, sacrifice, and resourceful behaviors (e.g., "I don't only study what [the professor] tells us we're supposed to study, I go over everything ... ask myself questions, have my neighbor quiz me ... it's about making a goal and working towards it"; S2, score of 46). 
Importantly, our qualitative findings portray a more nuanced and deeper understanding of the attributions of low- and high-scoring students than a quantitative study could have provided. Specifically, even though both low and high scorers described not always putting in the necessary effort or found the test or assignment difficult, high scorers felt confident in their ability to work harder next time and enhance their study habits (i.e., high control), whereas low scorers had a very difficult time even trying to apply themselves (especially when the material was more challenging) and had poor perceived control over improving their work ethic, often resulting in feelings of helplessness. It is therefore not surprising that, when asked to report on a single disappointment in quantitative studies, high-scoring students were less likely than low-scoring students to list "a lack of effort" (e.g., Kennett \& Keefer, 2006).

\section{Theme 4: Coping and learning following disappointment}

High and low scorers adopted different coping responses for dealing with academic disappointments. Low scorers engaged in wishful thinking, hoping for good grades in the future (e.g., "I just kept on going with the course, hoping I would improve and I'd at least pass ... But I didn't"; S17, score of -10) and reflecting on past disappointments, wishing they were different (e.g., "I wish I'd studied harder, but that's always the case for me"; S4, score of -8). Two common forms of wishful thinking were that things would magically be better next time (e.g., "I was like, 'Ok next time I'll do better' and then I didn't do better next time”; S3, score of -16) and, when reflecting on past disappointments, that things would be easier - they "just needed to do it" or "just do better"-yet, without specifically saying how they would do things differently (e.g., "I didn't work hard [in grade 12 calculus] because I didn't enjoy it. [I would change my mark in that class by] just working harder”; S7, score of 5).

Another common strategy employed by low scorers was actively trying to ignore disappointments, especially when they blamed themselves for disappointments (e.g., "I get disappointed, get really depressed, and at some point I just say, 'I can't deal with you right now' ... and I put it away"; S5, score of -15). Ironically, despite trying to forget their disappointments, they also ruminated about them (e.g., "I don't turn [my upset feelings] into studying more right then and there ... I don't really do anything except wallow in my sadness"; S6, score of 9). Dwelling on a disappointment was similarly common when low-SCS scorers blamed others/the university system (e.g., "It just irks me that I failed one of my courses by one percent ... One measly fricking percent"; S5, score of -15).

Although the high scorers also experienced sadness, anger, and frustration, they did not try to actively ignore these negative feelings, dwell on disappointment, or engage in wishful thinking. Instead, they used these emotions as motivation to direct problem-focused coping strategies and prevent subsequent disappointments from happening again (e.g., "[I'm] just sad in that moment, and then [that feeling] is almost like a booster to get you to work harder, and then I move on"; S12, score of 51).

Two high scorers said they found it helpful to let go of disappointments by talking through their feelings with family and friends (e.g., "I did call my mother, after I finished the exam, because it was bad. But I also call my mother about good things as well"; S15, score of 41). Although one of the low scorers also used friends and her mother to unload her feelings, it was not with the intention of trying to move forward: "When things are really bad, I call my mom and 
I just vent, or I go to a friend's house and ... completely just rip on everything that's happening" (S3, score of -16).

The different coping responses between those who score high and those who score low on the SCS have been observed in other quantitative and qualitative investigations. For example, Akgun (2004) found that students who scored high on the SCS used more effective coping strategies, such as problem solving, positively reappraising the situation, and seeking social support, and fewer maladaptive coping strategies, such as avoidance, when dealing with academic stress, than did those students who scored lower on the SCS. In Kennett et al. (2008), a qualitative study on coping with chronic pain, clients who scored high on the self-control scale accepted their chronic pain, moved forward with other things in life, and utilized and adapted the pain-coping strategies they were taught in the program. Conversely, clients having low scores continued to dwell on their pain and feelings of frustration, forgot the strategies they were taught, and described relying on pain killers or "simply ignoring" their pain and hoped at some point to find a cure.

Learning from disappointments also differed between those who scored low and high on the SCS. High scorers discussed learning new skills (e.g., "I was more used to writing in a scientific way. So [from that disappointment] I learned how to write reflectively"; S1, score of 38) and changing certain behaviors (e.g., S12 learned to finish assignments before hanging out with friends). Low scorers, in contrast, either failed to understand why they were receiving poor grades (e.g. "I failed the midterm, and I was just so disappointed ... I just can't seem to get [a 60]”; S17, score of -10) or knew what the problem was but were unable to implement a plan to successfully change their poor study habits on their own (e.g., "I always procrastinate so much, and I try to get rid of those habits but ... I'm not really learning from my experiences"; 44 , score of -8 ).

\section{Theme 5: It's a social world, after all!}

All of the participants described the social side of university life, including experiences with social stress, positive social interactions, relying on others in order to succeed academically, and seeking help from others as a supplemental resource. Specifically, three of the students scoring low on the SCS described experiencing some form of social stress, including family or roommate tensions that was interfering with their academic performance at university (e.g., "Social-wise, the last few months I had some complications with my roommates"; S17, score of -10). One of these students (S5) also described feelings of social isolation: "In terms of social life [here], I don't really have one. I barely know anyone." However, S16, with a score of -8 , who was taking her grandfather's advice to be more self-kind, described having good social support: "It took a lot of me to change the [negative and stressful] way I was thinking about myself... thank God for good friends". The high scorers also expressed having positive social interactions at university: "It was a really big experience for me to come to a place where you don't know anyone. But I found it fun, I made friends easily" (S12, score of 51).

Four low scorers depended on help from others or external interventions (e.g., "After I do poorly, I try harder to get help. I don't necessarily work harder on my own”; S7, score of 5), but other low scorers refused to seek help from others despite being unable to productively cope with their stress (e.g., "I don't want to ask for help"; S3, score of -16). Moreover, the friends of three low scorers controlled their bad and good study behaviors (e.g., "My roommate is taking Biology with me, and she is slacking off, so it makes me want to slack off... [Whereas when another friend and I] study [for 
Statistics] together, she pushes me to do practice questions, to do readings"; S17, score of -10). Conversely, four high scorers used others as a resource (e.g., "Sometimes it's good to study with other people, and even people that are in higher levels of education because they know more"; S20, score of 42). Family bonds were viewed by high scorers as a source of encouragement (e.g., "I'm working to better myself, I'm working to make my family proud"; S2, score of 46) or comfort after experiencing disappointments (e.g., "[My mom] is the one saying ... 'a lot of people are really happy to get an 85 ”"; S1, score of 38 ).

These findings align with those of other qualitative studies. For instance, in the study described by Kennett et al. (2008), those who scored low on the SCS were solely dependent on the program's staff for coping with pain, and they were at a loss without this support once the program ended, whereas those who scored high created other social support opportunities once the program was completed, alongside the use of their personal strategies. Comparably, Fast and Kennett (2015) found that although those who score high on the SCS enjoyed the company of others, they would exercise alone when friends declined to join them. Low scorers, in contrast, relied on other people to engage in exercise and blamed them for sabotaging their exercise goals had they decided to do something else instead.

\section{Negative Case: S14}

One low scorer (S14, score of 7$)$ was considered to be a negative case, given her descriptive use of problem-solving strategies to succeed (e.g., "I go over the assignment outline, and I break the assignment into chunks ... And when I sit down to write ... there's no music or anything and I'm just like, 'Ok. I'm typing this paper out'”) and was excluded from the thematic analysis. Although there was strong consistency between her problem-solving discourse and her choices of very/rather characteristic of me for the problem-solving items on the SCS, lowering her score were her less resourceful responses for other dimensions and items of the SCS, including her ability to delay immediate gratification.

Interestingly, during her interview, this student said she used to procrastinate with assignments: "[Now] I give myself a couple weeks. Whereas before [in college] ... I'd be like, 'Oh, it's the night before, let's write a paper' and it didn't always turn out the best." Possibly she struggled with delaying immediate gratification in other areas of her life. A second possibility is that she was in the process of becoming more resourceful. For instance, S14 attended college before university and conveyed, "I'll be going into my fifth year of postsecondary. So I have a groove ... I know now what specific tasks I start with and I just cross them off one by one and double check everything before I'm done." It is also conceivable that her resourcefulness skills were slowly evolving over time from the backing and advice of others that she described. Even though extant research provides evidence for the primary acquisition of resourcefulness skills in childhood and early adolescence (Leung \& He, 2010; Zauszniewski, Chung, Chang, \& Krafcik, 2002), other studies show that, with the proper social supports in place, resourcefulness skills can begin to evolve during late adolescence (Kennett \& Reed, 2009; Reed, Kennett, Lewis, \& Lund-Lucas, 2011) and even in late adulthood (Zauszniewski, 1997).

\section{LIMITATIONS}

Although contrasting how students scoring high versus low in resourcefulness explained, coped with, and learned from academic disappointments is a strength of this study, no causal relationships can be made. Moreover, because we and the practicum student who independently analyzed the data all 
have a background in psychology, it is likely that we had similar perspectives and biases. Additionally, it is difficult to say whether the results can be generalized to students at different universities, especially those in other countries and belonging to different cultures, given the sample was predominantly Canadian; albeit dealing with academic setbacks is a common phenomenon for most students worldwide. Noteworthy, S2 was from the Caribbean and her interview rhetoric was congruent with other high scorers in our sample.

\section{CONCLUSIONS AND FUTURE RESEARCH}

The aim of this study was to gain rich insights by comparing and contrasting the lived experiences with academic disappointments of students scoring low and high on Rosenbaum's Self-Control Schedule, with the ultimate goal of understanding how to help students succeed academically. The five themes that emerged, showcasing the differences between low and high scorers, were consistent with the findings of past quantitative research on Rosenbaum's self-control model and academic success (e.g., Akgun, 2004; Kennett \& Keefer, 2006; Reed \& Kennett, 2017). Moreover, our design allowed for the unraveling of why and how disappointments unfolded. Low scorers in our study were unsure about their academic ability; exhibited helplessness by attributing academic successes and disappointments to factors they perceived were beyond their control; and did not engage in resourceful academic behaviors following disappointments, instead trying to forget about them or excessively relying on others to get a passing grade. High scorers, on the other hand, were academically efficacious; achieved successes; overcame academic disappointments by working harder, employing academic-related positive self-talk and problem-solving strategies; and used social supports only as a resource.

Importantly, the five themes have a common thread: those who scored high on the SCS had control over their behaviors and the outcomes that followed, whereas those who scored low described feeling "lost" and "helpless." Hence, it would be beneficial for universities to help students to develop a sense of control over their studies. Fortunately, academic success and self-management training programs involving weekly seminars on topics ranging from problem solving and learning strategies to research skills to motivation have been effective at helping students learn resourceful and academic skills and modify their negative academic beliefs (Bowering, Mills, \& Merritt, 2017; Kennett, 1994; Kennett \& Reed, 2009; Reed et al., 2011; Reed et al., 2009). Whereas resourceful behaviors are thought to be acquired in childhood and early adolescence through informal interactions with parents and significant others, particularly resourceful others adopting a warm, loving, and supportive parenting style (Rosenbaum, 1990; Turkel \& Tezer, 2008; Zauszniewski et al., 2002), formal and extensive instruction of general and academic-specific resourceful behaviors by supportive and encouraging instructors who are knowledgeable in education techniques is important at the university level (Bowering et al., 2017). Academic success and self-management programs, therefore, focus on formally teaching key academic and resourcefulness skills, such as writing and editing skills, library research skills, time management and planning skills, deep learning strategies, goal-setting techniques, and constructively coping with academic stress, and these often extend over the course of an entire academic semester (see Bowering et al., 2017; Kennett, 1994 for details about course content). Encouragingly, students initially scoring lower on the SCS and who completed Kennett's (1994) program showed the greatest gains in resourcefulness and self-efficacy; however, those who scored extremely low on the SCS were the most likely to drop out, possibly because, as we observed in our study, they beat themselves up about failures, 
thus furthering their feelings of helplessness. Whether including self-compassion training within these academic success and self-management programs helps these low-scoring students respond to setbacks with more self-kindness and less self-judgment, thus, in turn, helping them persevere in an academic success or self-management course and gain resourceful behaviors, is an important task for future research. Dr. Neff's website (2019) offers resources on self-compassion exercises, meditations, and training, which could be incorporated into a pilot study of a combined academic success-selfcompassion course. Additionally, attributional retraining is effective at reframing students' attributions for disappointment from uncontrollable to controllable sources (see Haynes et al., 2009 for more information) and might, therefore, help increase low scoring students' sense of control and reduce their feelings of helplessness. However, we believe this attributional retraining should be used in conjunction with the teaching of resourcefulness skills, since without learning how to effectively study, manage time, cope with stress, and other resourceful behaviors, it is likely the low-scoring students would fall back into the cycle of learned helplessness.

In conclusion, students come to university with varying levels of resourcefulness skills, which is not surprising given Rosenbaum's argument that individuals differ in their learning histories of skills and behaviors more broadly and should therefore also differ in their acquisition of resourcefulness skills and behaviors. Students scoring low on the SCS in our study were unaware of how to implement effective study strategies, unmotivated to work hard, possessed a pessimistic explanatory style for both successes and disappointments, experienced difficulties learning from academic disappointments, and earned lower grades, thus putting themselves at greater risk of dropping out of university. Nonetheless, the aforementioned studies show that universities can play a crucial role in helping students gain the necessary resourcefulness skills to succeed academically by implementing academic success or selfmanagement (and perhaps self-compassion) training programs and perhaps targeting these programs to students in their first year of study (Bowering et al., 2017).

Rebecca D. Martin completed this research in partial fulfillment of her Master of Arts degree in psychology at Trent University (CAN). She currently works with Trent University's Health, Environment, and Indigenous Communities Research Group, where she provides data analysis support on food security projects.

Deborah J. Kennett is Professor Emeritus at Trent University (CAN). Her research focuses on academic self-regulation with special emphasis on program development and on the personal and social factors influencing academic success and university adjustment.

\section{REFERENCES}

Akgun, S. (2004). The effects of situation and learned resourcefulness on coping responses. Social Behaviour and Personality, 32(5), 441-448. https://doi.org/10.2224/sbp.2004.32.5.441

Akgun, S., \& Ciarrochi, J. (2003). Learned resourcefulness moderates the relationship between academic stress and academic performance. Educational Psychology, 23(3), 287-294. https://doi.org/10.1080/0144341032000060129

Ando, H., Cousins, R., \& Young, C. (2014). Achieving saturation in thematic analysis: Development and refinement of a codebook. Comprehensive Psychology, 3, 03-CP. https://doi.org/10.2466/03.CP.3.4

Boonpongmanee, C., Zauszniewski, J. A., \& Boonpongmanee, S. (2002). Psychometric properties of the selfcontrol schedule: Thai version. Research in Nursing and Health, 25(6), 471-478. https://doi.org/10.1002/nur.10058 
Bowering, E. R., Mills, J., \& Merritt, A. (2017). Learning how to learn: A student success course for at risk students. Canadian Journal for the Scholarship of Teaching and Learning, 8(3), 1-14. https://doi.org/10.5206/cjsotlrcacea.2017.3.12

Breines, J. G., \& Chen, S. (2012). Self-compassion increases self-improvement motivation. Personality and Social Psychology Bulletin, 38(9), 1133-1143. https://doi.org/10.1177/0146167212445599

Corbin, J. M., \& Strauss, A. L. (2008). Basics of qualitative research: Techniques and procedures for developing grounded theory. Thousand Oaks, California, USA: Sage.

Fast, H. V., \& Kennett D. J. (2015). Development and practical implications of the exercise resourcefulness inventory. Patient Education and Counseling, 98(5), 627-632. https://doi.org/10.1016/j.pec.2015.02.004

Fishbach, A., \& Choi, J. (2012). When thinking about goals undermines goal pursuit. Organizational Behavior and Human Decision Processes, 118(2), 99-107. http://dx.doi.org/10.1016/j.obhdp.2012.02.003

Francis, J. J., Johnston, M., Robertson, C., Glidewell, L., Entwistle, V., Eccles, M. P., \& Grimshaw, J. M. (2010). What is an adequate sample size? Operationalising data saturation for theory-based interview studies. Psychology and Health, 25(10), 1229-1245. https://doi.org/10.1080/08870440903194015

Freund, A. M., \& Hennecke, M. (2012). Changing eating behaviour vs. losing weight: The role of goal focus for weight loss in overweight women. Psychology \& Health, 27(Sup2), 25-42 https://doi.org/10.1080/08870446.2011.570867

Giorgi, A. (2009). The descriptive phenomenological method in psychology: A modified Husserlian approach. Pittsburgh, PA: Duquesne University Press.

Guest, G., Bunce, A., \& Johnson, L. (2006). How many interviews are enough? An experiment with data saturation and variability. Field methods, 18(1), 59-82. http://dx.doi.org/10.1177/1525822X05279903

Haynes, T. L., Perry, R. P., Stupnisky, R. H., \& Daniels, L. M. (2009). A review of attributional retraining treatments: Fostering engagement and persistence in vulnerable college students. In J. C Smart (Ed.), Higher Education: Handbook of Theory and Research: Vol. 24 (pp. 227-272). Dordrecht: Springer

Huang, C., Sousa, V. D., Chen, H., Tu, S., Chang, C., \& Pan, I. (2007). Stressors, depressive symptoms, and learned resourcefulness among Taiwanese adults with Diabetes Mellitus. Research and Theory for Nursing Practice: An International Journal, 21(2), 83-97. https://doi.org/10.1891/088971807780852066

Katz, R. C., \& Singh, N. N. (1986). A comparison of current smokers and self-cured quitters on Rosenbaum's selfcontrol schedule, Addictive Behaviors, 11, 63-65. https://doi.org/10.1016/0306-4603(86)90011-0

Kennett, D. J. (1994). Academic self-management counselling: Preliminary evidence for the importance of learned resourcefulness on program success. Studies in Higher Education, 19(3), 295-307. https://doi.org/10.1080/03075079412331381890

Kennett, D. J., \& Ackerman, M. (1995). Importance of learned resourcefulness to weight loss and early success during maintenance: Preliminary evidence. Patient Education and Counseling, 25(2), 197-203. https://doi.org/10.1016/0738-3991(95)00713-A

Kennett, D. J., \& Keefer, K. (2006). Impact of learned resourcefulness and theories of intelligence on academic achievement of university students: An integrated approach. Educational Psychology, 26(3), 441-457. https://doi.org/10.1080/01443410500342062

Kennett, D. J., O'Hagan, F. T., \& Cezer, D. (2008). Learned resourcefulness and the long-term benefits of a chronic pain management program. Journal of Mixed Methods Research, 2(4), 317-339. https://doi.org/10.1177/1558689808319732

Kennett, D. J., \& Reed, M. J. (2009). Factors influencing academic success and retention following a 1st-year postsecondary success course. Educational Research and Evaluation, 15(2), 153-166. https://doi.org/10.1080/13803610902804382

Kennett, D. J., Reed, M. J., \& Stuart, A. S. (2013). The impact of reasons for attending university on academic resourcefulness and adjustment. Active Learning in Higher Education, 14(2), 123-133. https://doi.org/10.1177/1469787413481130

Kiefer, J. (2002). A cross validation of the self-control schedule (unpublished doctoral dissertation), California School of Professional Psychology, San Diego, California.

Krause, K., \& Freund, A. M. (2014). How to beat procrastination: The role of goal focus. European Psychologist, 19(2), 132-144. http://dx.doi.org/10.1027/1016-9040/a000153 
Leung, G. S. M., \& He, X. (2010). Resourcefulness: A protective factor buffer against the academic stress of schoolaged children. Educational Psychology, 30(4), 395-410. https://doi.org/10.1080/014434111003682574

Lévesque, L., Gauvin, L. \& Desharnais, R. (2003). Maintaining exercise involvement: the role of learned resourcefulness in process of change use. Psychology of Sport and Exercise, 4(3), 237-253. https://doi.org/10.1016/S1469-0292(02)00007-9

Martin, R. D., \& Kennett, D. J. (2018). To be kind or not to be kind: The moderating role of self-compassion in the relationship between general resourcefulness and academic self-regulation. Journal of Social Psychology, 158(5), 626-638. https://doi.org/10.1080/00224545.2017.1407286

Menshadi, N., Bar-Tal, Y., \& Barnoy, S. (2013). The relationship between learned resourcefulness and cancerrelated fatigue in patients with non-Hodgkin lymphoma. Oncology Nursing Forum, 40(2), 133-138. https://onf.ons.org/onf/40/2/relationship-between-learned-resourcefulness-and-cancer-related-fatiguepatients-non

Nakano, K. (1995). Assessment of self-control behavior: Validity analyses on a Japanese version of the self-control schedule. Journal of Clinical Psychology, 51(3), 378-382. http://dx.doi.org/10.1002/10974679(199505)51:3<378::AID-JCLP2270510309>3.0.CO;2-N

Neff, K. (2003). Self-compassion: An alternative conceptualization of a healthy attitude toward oneself. Self and Identity, 2(2), 85-101. https://doi.org/10.1080/15298860309032

Neff, K. (2019). Self-compassion. Retrieved from http://self-compassion.org/

Neff, K., Hsieh, Y., \& Dejitterat, K. (2005). Self-compassion, achievement goals, and coping with academic failure. Self and Identity, 4(3), 263-287. https://doi.org/10.1080/13576500444000317

Ngai, F., Chan, S. W., \& Holroyd, E. (2008). Translation and validation of a Chinese version of the self-control schedule in Chinese childbearing women. Journal of Clinical Nursing, 17(3), 323-332. http://dx.doi.org/10.1111/j.1365-2702.2006.01882.x

Perry, R. P. (2003). Perceived (academic) control and causal thinking in achievement settings. Canadian Psychology/Psychologie canadienne, 44(4), 312-331. http://dx.doi.org/10.1037/h0086956

Redden, E. M., Tucker, R. K., \& Leslie, Y. (1983). Psychometric properties of the Rosenbaum schedule for assessing self-control. Psychological Record, 33(1), 77-86. https://doi.org/10.1007/BF03394824

Reed, M. J., \& Kennett, D. J. (2017). The importance of university students' perceived ability to balance multiple roles: A comparison of students with and without disabilities. Canadian Journal of Higher Education/La Revue canadienne d'enseignement supérieur, 47(2), 71-86. Retrieved from http://journals.sfu.ca/cjhe/index.php/cjhe/article/view/187965

Reed, M. J., Kennett, D. J., Lewis, T., \& Lund-Lucas, E. (2011). The relative benefits found for students with and without learning disabilities taking a first-year university preparation course. Active Learning in Higher Education, 12(2), 133-142. https://doi.org/10.1177/1469787411402483

Reed, M. J., Kennett, D. J., Lewis, T., Lund-Lucas, E., Stallberg, C., \& Newbold, I. L. (2009). The relative effects of university success courses and individualized interventions for students with learning disabilities. Higher Education Research and Development, 28(4), 385-400. https://doi.org/10.1080/07294360903067013

Rosenbaum, M. (1980). A schedule for assessing self-control behaviors: Preliminary findings. Behavior therapy, 11(1), 109-121. https://doi.org/10.1016/S0005-7894(80)80040-2

Rosenbaum, M. (1990). The role of learned resourcefulness in the self-control of health behavior. In M. Rosenbaum (Ed.), Learned resourcefulness: On coping skills, self-control, and adaptive behavior (pp. 3-30). New York, NY: Springer.

Rosenbaum, M., \& Ben-Ari, K. (1985). Learned helplessness and learned resourcefulness: Effects of noncontingent success and failure on individuals differing in self-control skills. Journal of Personality and Social Psychology, 48(1), 198-215. http://dx.doi.org/10.1037/0022-3514.48.1.198

Rosenbaum, M., \& Ben-Ari Smira, K. (1986). Cognitive and personality factors in the delay of gratification of hemodialysis patients. Journal of Personality and Social Psychology, 51(2), 357-364. http://dx.doi.org/10.1037/0022-3514.51.2.357

Seligman, M. E. P. (1991). Learned optimism. New York, NY: Knopf.

Turkel, Y. D., \& Tezer, E. (2008). Parenting styles and learned resourcefulness of Turkish adolescents. Adolescence, 43(169), 143-152. 
Weiner, B. (1979). A theory of motivation for some classroom experiences. Journal of Educational Psychology, 71(1), 3-25. http://dx.doi.org/10.1037/0022-0663.71.1.3

Weiner, B. (1986). An attributional theory of achievement motivation and emotion. New York, NY: Springer. Willig, C. (2013). Introducing qualitative research in psychology (3rd ed.). Maidenhead: Open University Press. Zauszniewski, J. A. (1997). Evaluation of a measure of learned resourcefulness for elders. Journal of Nursing Measurement, 5(1), 71-86.

Zauszniewski, J. A., Chung, C. W., Chang, H., \& Krafcik, K. (2002). Predictors of resourcefulness in school-aged children. Issues in Mental Health Nursing, 23(4), 385-401. https://doi.org/10.1080/01612840290052587

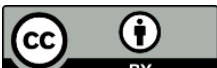

Copyright for the content of articles published in Teaching \& Learning Inquiry resides with the authors, and copyright for the publication layout resides with the journal. These copyright holders have agreed that this article should be available on open access under a Creative Commons Attribution License 4.0 International (https://creativecommons.org/licenses/by/4.0). The only constraint on reproduction and distribution, and the only role for copyright in this domain, should be to give authors control over the integrity of their work and the right to be properly acknowledged and cited, and to cite Teaching \& Learning Inquiry as the original place of publication. Readers are free to share these materials-as long as appropriate credit is given, a link to the license is provided, and any changes are indicated. 